Cochrane Database of Systematic Reviews

\title{
Positioning and spinal bracing for pain relief in metastatic spinal cord compression in adults (Review)
}

Lee SH, Grant R, Kennedy C, Kilbride L

Lee SH, Grant R, Kennedy C, Kilbride L.

Positioning and spinal bracing for pain relief in metastatic spinal cord compression in adults.

Cochrane Database of Systematic Reviews 2015, Issue 9. Art. No.: CD007609.

DOI: 10.1002/14651858.CD007609.pub3.

www.cochranelibrary.com 
TABLE OF CONTENTS

ABSTRACT

PLAIN LANGUAGE SUMMARY

BACKGROUND

OBJECTIVES

METHODS

RESULTS

Figure 1.

DISCUSSION

AUTHORS' CONCLUSIONS

ACKNOWLEDGEMENTS

REFERENCES

CHARACTERISTICS OF STUDIES

APPENDICES

WHAT'S NEW

HISTORY

CONTRIBUTIONS OF AUTHORS

DECLARATIONS OF INTEREST

SOURCES OF SUPPORT

DIFFERENCES BETWEEN PROTOCOL AND REVIEW

INDEX TERMS

1

2

3

4

4

5

6 
[Intervention Review]

\section{Positioning and spinal bracing for pain relief in metastatic spinal cord compression in adults}

Siew Hwa Lee ${ }^{1}$, Robin Grant ${ }^{2}$, Catriona Kennedy ${ }^{1}$, Lynn Kilbride ${ }^{3}$

1Department of Nursing and Midwifery, Faculty of Education and Health Sciences, University of Limerick, Limerick, Ireland. ${ }^{2}$ Edinburgh Centre for Neuro-Oncology (ECNO), Western General Hospital, Edinburgh, UK. ${ }^{3}$ Nursing and Community Health, Glasgow Caledonian University, Glasgow, UK

Contact: Siew Hwa Lee, Department of Nursing and Midwifery, Faculty of Education and Health Sciences, University of Limerick, Health Sciences Building, Room HS3-029, Limerick, Ireland. siew.lee@ul.ie.

Editorial group: Cochrane Pain, Palliative and Supportive Care Group.

Publication status and date: Stable (no update expected for reasons given in 'What's new'), published in Issue 9, 2015.

Citation: Lee SH, Grant R, Kennedy C, Kilbride L. Positioning and spinal bracing for pain relief in metastatic spinal cord compression in adults. Cochrane Database of Systematic Reviews 2015, Issue 9. Art. No.: CD007609. DOI: 10.1002/14651858.CD007609.pub3.

Copyright @ 2015 The Cochrane Collaboration. Published by John Wiley \& Sons, Ltd.

\section{A B S T R A C T}

\section{Background}

This is an updated version of the original Cochrane review published in Issue 3 (Lee 2012) on patient positioning (mobilisation) and bracing for pain relief and spinal stability in adults with metastatic spinal cord compression.

Many patients with metastatic spinal cord compression (MSCC) have spinal instability, but their clinician has determined that due to their advanced disease they are unsuitable for surgical internal fixation. Mobilising may be hazardous in the presence of spinal instability as further vertebral collapse can occur. Current guidance on positioning (whether a patient should be managed with bed rest or allowed to mobilise) and whether spinal bracing is helpful, is contradictory.

\section{Objectives}

To investigate the correct positioning and examine the effects of spinal bracing to relieve pain or to prevent further vertebral collapse in patients with MSCC.

\section{Search methods}

For this update, we searched for relevant studies from February 2012 to 31 March 2015. We searched the Cochrane Central Register of Controlled Trials (CENTRAL), MEDLINE and MEDLINE In Process, EMBASE, AMED, CINAHL, TRIP, SIGN, NICE, UK Clinical Research Network, National Guideline Clearinghouse and PEDro database. We also searched the metaRegister of Controlled Trials (mRCT), ClinicalTrials.gov, UK Clinical Trials Gateway (UKCTG), WHO International Clinical Trials Registry Platform (ICTRP) and Australia New Zealand Clinical Trials Registry (ANZCTR).

For the original version, we searched the Cochrane Central Register of Controlled Trials (CENTRAL), MEDLINE, EMBASE, CINAHL, CANCERLIT, NICE, SIGN, AMED, TRIP, National Guideline Clearinghouse, and PEDro database, in February 2012.

\section{Selection criteria}

We selected randomised controlled trials (RCTs) of adults with MSCC of interventions on positioning (mobilisation) and bracing.

\section{Data collection and analysis}

Two review authors independently assessed each possible study for inclusion and quality. 


\section{Main results}

For the original version of the review, we screened 1611 potentially relevant studies. No studies met the inclusion criteria. Many papers identified the importance of mobilisation, but no RCTs of bed rest versus mobilisation have been undertaken. We identified no RCTs of bracing in MSCC.

For this update, we identified 347 potential titles. We screened 300 titles and abstracts after removal of duplicates. We did not identify any additional studies for inclusion.

\section{Authors' conclusions}

Since publication of the original version of this review, no new studies were found and our conclusions remain unchanged.

There is a lack of evidence-based guidance around how to correctly position and when to mobilise patients with MSCC or if spinal bracing is an effective technique for reducing pain or improving quality of life. RCTs are required in this important area.

\section{PLAIN LANGUAGE SUMMARY}

\section{Position and spinal bracing for pain relief in adults with metastatic spinal cord compression}

Metastatic spinal cord compression (MSCC) is a serious complication of advanced cancer that can cause pain and mobility (movement) problems as well as paralysis. For many patients, a diagnosis of MSCC indicates the final stages of their illness. The spread of cancer to the spinal column can make walking unsafe. However, staying in bed risks deep vein thrombosis or pressure sores. Supporting the spine with spinal bracing (neck, thoracic spine, or lumbar support) may prevent further spinal collapse, but may be uncomfortable or ineffective.

Managing this condition is challenging for healthcare professionals. Some existing guidelines suggest bed rest (avoiding movement) and the use of spinal braces. However, positioning (for example lying flat, sitting up, standing or walking) and the use of spinal braces needs to be balanced against the patient's wishes, ensuring their comfort and individual preferences. If the spine is unstable, movement may cause more pain and risk further spinal cord or nerve root damage. Spinal bracing may be supportive and reduce pain and risk of collapse. However, spinal bracing may not prevent further collapse and spinal cord damage, and may be uncomfortable. If life expectancy is short, then a palliative care approach focusing on patient preferences and priorities is appropriate.

This review update attempted to find the existing evidence on positioning and spinal bracing for adults with MSCC. We ran updated searches in March 2015. We found no randomised clinical trials comparing positioning (bed rest versus mobilisation), or spinal bracing to no bracing, for pain relief. In the absence of clear evidence, healthcare professionals and patients need to discuss the options to decide what is best for the individual patient.

For this update, no new studies were found and our conclusions remain unchanged. There is a need for randomised controlled clinical trials to find out which treatment is most effective. 


\section{B A C K G R O U N D}

This is an updated version of the original Cochrane review published in Issue 3 (Lee 2012) on patient positioning (mobilisation) and bracing for pain relief and spinal stability in adults with metastatic spinal cord compression.

\section{Description of the condition}

Metastatic spinal cord compression (MSCC) is a serious complication of cancer disease. The symptoms of MSCC range from minor sensory disturbance and autonomic changes to severe pain and irreversible paralysis. MSCC is defined as "compression of the dural sac and its contents (spinal cord and/or cauda equine) by an extradural tumour mass. Clinical features include any or all of the following; pain (local or radicular), weakness, sensory disturbance and/or evidence of sphincter dysfunction" Loblaw 1998. The onset of MSCC is a medical emergency and warrants immediate intervention to minimise damage to the spinal cord and preserve neurological function. Prognosis and the quality of life are related to the patient's pretreatment ambulatory status, and rapid diagnosis and treatment are required (Levack 2002).

Controversy surrounds the care of patients with MSCC. Approximately 10 people per 100,000 a year suffer from this condition, and their prognosis is known to be very poor (Levack 2002; Posner 1995). Current acceptable treatment approaches for MSCC include corticosteroids, radiotherapy, and surgery (Loblaw 1998). A course of the corticosteroid dexamethasone is prescribed to reduce the oedema and cord compression and thereby relieve pain. There is some controversy regarding the optimal dose of dexamethasone. The standard dose administered is $16 \mathrm{mg} / \mathrm{d}$, in divided doses, over several days. The most common treatment for MSCC is radiotherapy alone. Radiation therapy reduces the tumour mass, thereby alleviating pain and relieving the spinal cord compression. Regimens of radiation therapy for spinal cord compression vary; the commonly prescribed regimen is $3 \mathrm{~Gy}$ per fraction (Kwok 2005).

Surgery may be indicated, particularly for those with spinal instability or rapidly progressing loss of neurologic functions, but is usually limited to the small number of patients with involvement of one or two vertebrae and those who have good performance status and an expected survival of more than three months (Rades 2006). The effectiveness of surgery plus radiotherapy as opposed to radiotherapy alone has been debated; two studies claim that where the overall condition of the patient merits intervention, surgery plus radiotherapy may provide the best outcomes (Patchell 2005; Thomas 2006). Tokuhashi 2005 developed a prognostic indicator as part of the assessment for surgery, which uses six parameters (performance status, extraspinal bone metastases, quantity of metastases in the vertebral body, metastases to internal organs, primary site, and the severity of neurological damage). Bilsky 2007 and Gasbarrini 2010 have developed other tools to identify a patient's suitability for surgery. The NOMS (neurological assessment, oncologic assessment, mechanical instability, and systemic disease) framework developed by Bilsky 2007 and the algorithm for surgical treatment by Gasbarrini 2010 both require further evaluation. A study analysing cost-effectiveness found that surgery together with radiotherapy was likely to be costeffective, in comparison with radiotherapy alone, in the Canadian context (Thomas 2006). Due to lack of evidence and data from prospective randomised controlled trials (RCTs), the treatment of
MSCC remains controversial (Loblaw 1998; Makris 1995; Prasad 2005). Currently, care of patients with MSCC is based on individual clinician preference rather than evidence-based guidelines. The lack of such guidelines has been shown to cause delays and discrepancies in patient treatment (Levack 2002; McClinton 2006).

The role of bracing as a treatment for MSCC is not well defined (Lewandrowski 2006). Braces can be used postoperatively to maintain the integrity of the spine, although this treatment is criticised anecdotally as being pointless, as this is the purpose of the surgery. Braces can also be used long term to treat spinal instability; however, as the lifespan of a patient with MSCC may be short, their use in this context is limited (Lewandrowski 2006). While both the cervical and thoracic spine can be braced, cervical bracing is most commonly used in MSCC (Lewandrowski 2006). Positioning (or mobilisation) is a treatment that is prescribed preoperatively, postoperatively, and long term for people with MSCC. The prescription is usually bed rest or to mobilise. Bed rest usually refers to the patient being nursed supine, while to mobilise refers to allowing the patient to get out of bed and walk. Clinically, the rationale for bed rest is usually related to the spinal stability status (NICE 2008). An audit conducted by McClinton and Hutchison highlighted a lack of guidance on how to correctly position patients or whether or not to use braces (McClinton 2006). More recently, the National Institute for Health and Clinical Excellence (NICE) developed recommendations for the diagnosis and management of adults with MSCC in response to a recommendation from the Department of Health (NICE 2008). These represent the best available good-practice guidelines for managing patients with MSCC and allude to the use of bracing and positioning. However, the evidence that supports these recommendations is not conclusive.

\section{Description of the intervention}

Patients with an unstable spine or with unknown stability status are usually nursed in a supine position, and bed rest is recommended to prevent further vertebral collapse (NICE 2008; Pease 2004). There are conflicting opinions about these instructions, and some patients are encouraged to mobilise (Walji 2008).

The supine position can increase pressure and pain for MSCC patients, and there are several anecdotes of patients sleeping in an upright position in order to relieve the pain caused by lying supine (Bilsky 1999; Bilsky 2006; Gilbert 1978; Obbens 1987). Additionally, some patients experience a depressed mood when lying supine for extended periods of time (Pease 2004). Deep vein thrombosis, chest infection, pressure sores, and urinary tract infections can pose additional complications for patients who are lying supine (Pease 2004); one guideline suggests that patients with a short life expectancy should be in a sitting-up position in order to avoid the aforementioned complications related to bed rest (Jacobs 1999). A primary goal of healthcare professionals is to rehabilitate patients. However, concerns about causing pathological fractures may mean mobilisation is discouraged among patients with MSCC for fear of paralysis (Bunting 2001). Additionally, patients with spinal instability have reported that they suffer increased pain while sitting or standing due to an increased axial load on the spine (Bilsky 1999).

Bracing is an intervention that can be used to stabilise the spine through prevention or delay of further vertebral collapse; it also may reduce pain. Braces provide an additional form of 
external support to the affected area of the spine (Lewandrowsk 2006). The goals of spinal bracing are restriction of motion, realignment, and support (Benzel 2001). Both nursing and surgical guidelines recommend bracing for patients with cervical lesions (Mercadante 1997; NICE 2008; Schiff 2003; Yarbro 2005). Despite these recommendations, the use of bracing for patients with MSCC is controversial as there is currently no evidence base for the use or functionality of bracing in this group.

\section{Why it is important to do this review}

It was important to assess the evidence for correct positioning and the effects of spinal bracing to relieve pain or to prevent further vertebral collapse in patients with MSCC. It was also important to ensure that healthcare professionals could draw on this evidence to inform the care and management of patients with MSCC.

\section{OB JECTIVES}

To investigate the correct positioning and examine the effects of spinal bracing to relieve pain or to prevent further vertebral collapse in patients with MSCC.

\section{METHOD S}

\section{Criteria for considering studies for this review \\ Types of studies}

RCTs.

\section{Types of participants}

Adults of either gender with a confirmed diagnosis of MSCC.

\section{Types of interventions}

Interventions included spinal bracing and guidance for patients on positioning (for example lying flat, sitting up, standing or mobilised) or both, versus people who receive no therapy or no positioning guidance, or neither.

\section{Types of outcome measures}

\section{Primary outcomes}

1. Radiologically confirmed effects of bracing on vertebral collapse under physiological load measured by vertebral column collapse rate, number of vertebrae involved in the problem area, and bony impingement.

2. Participant-reported measures of pain relief, quality of life, and satisfaction. We planned to measure vertebral collapse by vertebral column collapse rate, number of vertebrae involved in the problem area, and bony impingement.

3. Reported adverse events.

Primary outcome measures should be measured using valid and reliable assessment tools (visual analogue scores and quality-oflife scales, for example European Organisation for Research and Treatment of Cancer (EORTC)).

\section{Search methods for identification of studies}

\section{Electronic searches}

For this update, we searched for relevant studies from February 2012 to 31 March 2015. However, we have excluded CANCERLIT and
PDQ databases which were listed in the original review. CANCERLIT is no longer available. We are confident that our updated searches have captured the relevant studies.

We searched the following databases without language restrictions:

- The Cochrane Central Register of Controlled Trials (CENTRAL) (via the Cochrane Library) (Issue 3, 2015)

- MEDLINE and MEDLINE In-Process (OVID) (February 2012 to 31 March 2015)

- EMBASE (OVID) (February 2012 to 31 March 2015)

- AMED (OVID) (February 2012 to 31 March 2015)

- CINAHL (EBSCO) (February 2012 to 31 March 2015)

- TRIP (February 2012 to 31 March 2015)

We also searched other websites in March 2015:

- SIGN (www.sign.ac.uk)

- NICE (www.nice.org.uk) guidance (http://www.nice.org.uk/ Guidance/CG75)

- UK Clinical Research Network (www.ukcrn.org.uk)

- National Guideline Clearinghouse (www.guideline.gov)

- PEDro (www.pedro.org.au)

We used 'medical subject headings' (MeSH) or equivalent and text word terms. We used no language restrictions. We tailored searches to individual databases and adapted them from those used in the original review. We have presented the search strategies used for the original review in Appendix 1 and the updated search strategies for this version in Appendix 2.

\section{Searching other resources}

For this update, we searched the following trials registries in March 2015 and found no ongoing studies that met our inclusion criteria.

- metaRegister of Controlled Trials (mRCT) (www.isrctn.com/ page/mrct)

- ClinicalTrials.gov (www.clinicaltrials.gov)

- UK Clinical Trials Gateway (UKCTG) (http:// www.ukctg.nihr.ac.uk/default.aspx)

- WHO International Clinical Trials Registry Platform (ICTRP) (http:apps.who.int/trialsearch/)

- Australia New Zealand Clinical Trials Registry (ANZCTR) (www.anzctr.org.au)

We examined the references of all studies identified as part of this review in order to identify further studies for inclusion. This search identified no further studies for inclusion.

\section{Data collection and analysis}

\section{Selection of studies}

Two review authors independently assessed each potentially eligible study for inclusion and for quality by reviewing the titles or abstracts. Disagreements over inclusion were resolved by discussion or by consulting a third review author, or both. 


\section{Data extraction and management}

We developed a data extraction form based on the Cochrane Pain, Palliative and Supportive Care Group template. We planned to extract the following main sets of data from each included study:

- lead author

- date

- study participant inclusion criteria

- participants (diagnoses, demographics, primary cancer site, gender, age)

- interventions (spinal bracing, positioning, pain relief)

- intervention setting (hospital, hospice, home)

- outcome measures (quality of life, pain scores)

- timing of outcome measures (upon diagnosis, postsurgery, postradiotherapy)

We identified at least two review authors to independently extract data into the data extraction form. One review author was to enter data into Review Manager (RevMan) (RevMan 2014), with the other checking the accuracy of this data input.

Any discrepancies were to be referred to a third review author and any errors or inconsistencies resolved.

We entered details of excluded studies into the 'Characteristics of excluded studies' table; if we had included studies, we would have entered them into a 'Characteristics of included studies' table. If necessary, we would have sought additional information from the principal investigator of a study for clarification of published data or missing data.

\section{Assessment of risk of bias in included studies}

We intended to assess any bias of included studies in accordance with guidelines in the Cochrane Handbook for Systematic Reviews of Interventions (Higgins 2011). Two review authors were to independently assess the risk of bias in included studies, with any disagreements to be resolved through discussion with a third review author as arbitrator if required. We were to contact study authors for additional information if required. We were to provide a written commentary of risk of bias within the review text. We would have assessed and graded methodological quality using the 'Risk of bias' table available in RevMan 5.3 (RevMan 2014).

\section{Measures of treatment effect}

We would have analysed data using The Cochrane Collaboration's Review Manager, version 5.3 software (RevMan 2014). As no studies met our inclusion criteria, it was not possible to measure the effects of intervention.

\section{RESULTS}

\section{Description of studies}

A PRISMA flow chart indicates the number of references identified in the searches, both for the original version of the review and the latest search. See Figure 1. 
Figure 1. Study flow diagram.

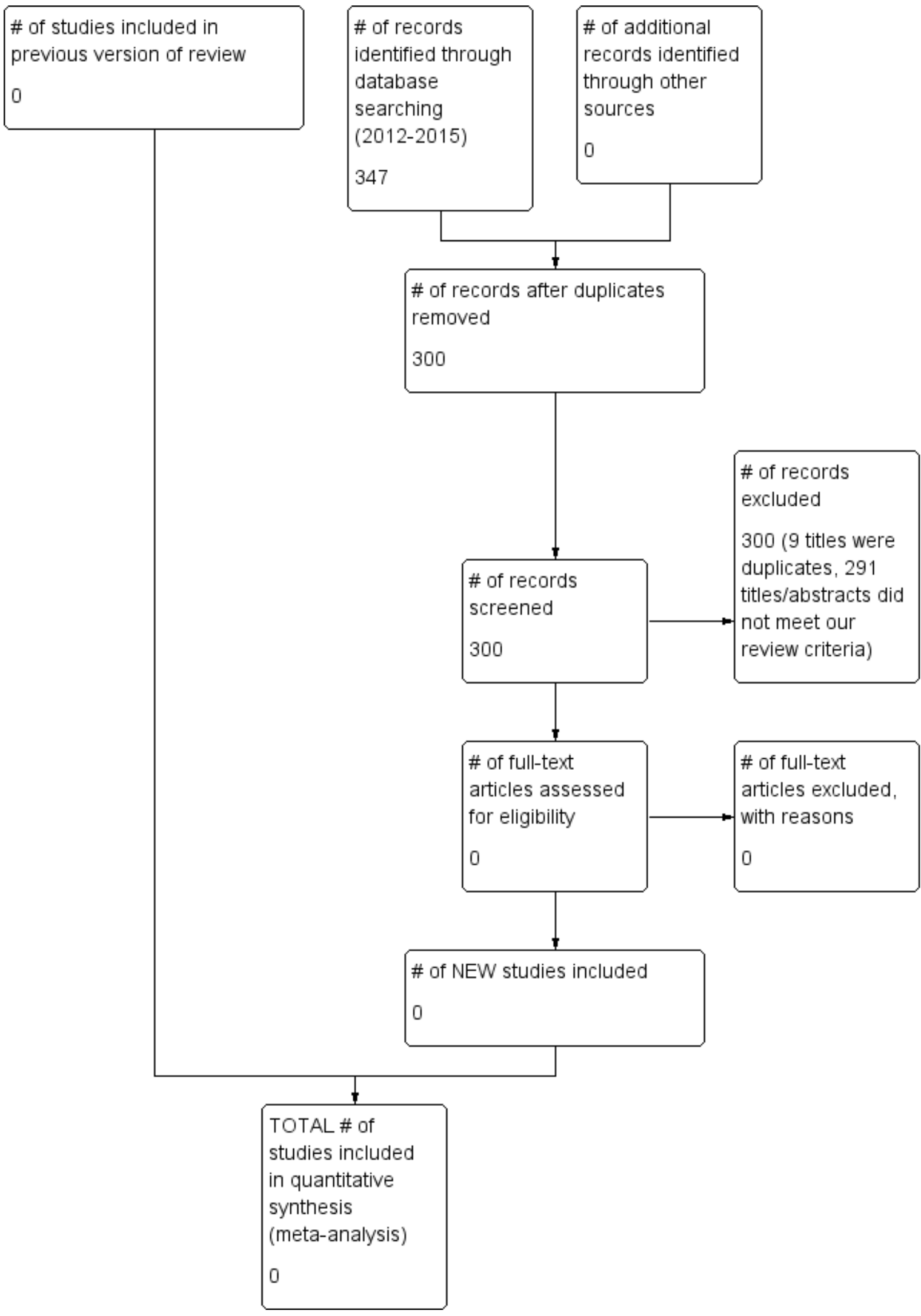




\section{Included studies}

Since publication of the original version of this review, we have found no new studies. The original review identified 1652 citations for screening, and the updated review identified 347 citations from February 2012 to 31 March 2015.

For this update, the searches identified 347 titles overall. Excluding duplicates, we included 300 titles/abstracts for initial screening. Of these, nine titles were duplicates and 291 titles/abstracts did not meet the criteria. Therefore, this updated search did not identify any RCTs for this review. Furthermore, we found no ongoing studies that met our inclusion criteria in the five clinical trials registries.

For the original review, the search strategy identified 1652 citations overall. We identified 41 duplicates. We identified and screened for retrieval a total of 1611 potentially relevant studies. We excluded abstracts that were not relevant to the review. For example, we identified a large number relating to the range of therapies offered to people with MSCC such as surgery and radiotherapy. We obtained full-text articles for 19 abstracts. We then excluded these as they were not reporting an RCT. We therefore found no studies meeting the inclusion criteria detailed above.

\section{Excluded studies}

For the original review, we retrieved eight articles as they reported positioning and bracing recommendations and the methods used were not clear from the abstract. We excluded seven of these eight articles because they were not RCTs (Freundt 2010; Furstenberg 2009; Galasko 1991; Ippolito 1998; Rades 2010; Sciubba 2010; Spinazze 2005). One further study was found to be an RCT but did not report in their findings the impact of the intervention measures (positioning and bracing) in terms of the outcomes detailed for this review (Chi 2009). We have detailed reasons for exclusion in the 'Characteristics of excluded studies' table. We identified no additional studies for exclusion in this update.

\section{Risk of bias in included studies}

As no studies met our inclusion criteria, it was not possible to analyse the risk of bias.

\section{Effects of interventions}

We would have analysed data using The Cochrane Collaboration's Review Manager 5 software (RevMan 2014). As no studies met our inclusion criteria, it was not possible to measure the effects of intervention.

\section{DISCUSSION}

Since the publication of the original version of this review, we have found no new studies. The original review found no studies for inclusion, and there is no difference in the updated version.

Bed rest and mobilisation, and spinal bracing, are interventions that are discussed within the literature to improve management of pain and prevent further vertebral collapse among patients with MSCC (McClinton 2006; Mercadante 1997; NICE 2008; Pease 2004). As the evidence to support these recommendations is controversial, this review aimed to investigate the correct positioning and examine the effects of spinal bracing to relieve pain or to prevent further vertebral collapse in patients with MSCC in order to assist healthcare professionals in their decision making.
We identified no studies within this review that provided evidence to support the positioning or bracing techniques that should be used to manage pain or prevent further vertebral collapse, or both, among patients with MSCC. However, we identified some studies that discussed these interventions and that may inform further studies or discussions. Four studies discussed the effect of positioning on pain (Bilsky 1999; Bilsky 2006; Bilsky 2007; Borm 2004). Bilsky suggested that when nursed in a supine position, patients suffered an increased pressure or pain due to increased axial load on the spine and provided anecdotal evidence that patients requested to sleep in an upright position to relieve pain (Bilsky 1999, Bilsky 2006, Bilsky 2007). Borm 2004 found that diagnosis of spinal tumours can be difficult if there are concurrent signs of degenerative changes in the spine. This study found no significant difference in the frequency of back pain either at rest or under loading for both spinal tumours and degenerative disease of the spine. It was observed that a combination of back pain at rest and without back pain under loading only occurred in people with spinal tumours, but these results were not statistically significant.

Some studies suggested that other factors than pain should be considered in positioning (Bilsky 1999; Bilsky 2007; Pease 2004). Pease 2004 report that some patients experienced a depressed mood when lying supine for extended periods of time, and that other complications such as deep vein thrombosis, chest infection, pressure sores, and urinary tract infections can pose difficulties. Jacobs 1999 suggest that in light of some of these findings, patients with short life expectancy should be encouraged to sit upright or to mobilise themselves.

We conclude that clear guidelines are needed to inform how to correctly position patients with MSCC in order to maintain spinal stability and relieve pain. We also suggest that when considering certain positions, such as lying supine, any additional physical and psychological factors that could affect patients because of this recommendation should be investigated.

There is currently no evidence base for the use or functionality of bracing. Some authors advise that when there is suspicion of cervical lesions, patients should be fitted with a cervical collar to help stabilise the spine and reduce neck movement (Maher de Leon 1998; Pease 2004). However, none of these authors have cited any original research or studies to support this statement. In fact, Heary 2001 points out that there is a lack of evidence for the long-term benefit of bracing in the literature, and that the (cervical) collar's effectiveness in preventing an impending pathological fracture is unknown.

In addition to potentially stabilising the spine, it is argued that a rigid spinal brace or orthosis may also help relieve pain and may be a conservative alternative to vertebroplasty (Galasko 1991; NICE 2008). Research studies are needed to clarify the role of bracing in MSCC and what effects bracing has on spine stabilisation, pain relief, and quality of life, and whether there is any overall benefit of external braces or orthoses for people with MSCC.

There is a gap in the evidence base to inform whether bed rest or mobilisation or bracing in individuals with MSCC is helpful. Despite published guidelines (NICE 2008), this review has demonstrated that evidence relating to spinal positioning and bracing is limited and inconclusive, and therefore further research is required in this area. 


\section{Summary of main results}

We intended to investigate whether patients with MSCC should remain in bed or mobilise, and to examine the effects of spinal bracing to relieve pain or prevent vertebral collapse. The overall aim of the review was to provide evidence to assist healthcare professionals with their decision making in this area. Unfortunately, the review process did not identify any studies that would guide healthcare professionals' decision making in this area. Furthermore, existing literature offers conflicting advice in terms of mobilisation and stabilisation.

We conclude that clear guidelines are needed to inform how to correctly position patients in order to maintain spinal stability and relieve pain. Guidelines recommend using a spinal orthosis to increase spinal stability and to relieve pain (NICE 2008; White 1978; White 1990), however we have concluded based on this review that there is no evidence to support this recommendation.

\section{AUTHORS' CONCLUSIONS}

\section{Implications for practice}

\section{People with MSCC}

There is a lack of evidence available to guide people with MSCC about the effectiveness of spinal bracing, positioning, or mobilisation. Quality of life, including pain relief and being able to mobilise, are important issues for people with MSCC and clinicians to consider when making decisions around the management of MSCC. Fear of doing further damage by mobilising must be balanced against the possible consequences for quality of life and physical health of inappropriate prolonged bed rest. There exists insufficient evidence to support one management plan over another. In the absence of clear evidence, healthcare professionals and people with MSCC need to discuss the options and come to an agreed management plan. Development of an appropriate clinical trial is required.

\section{Clinicians}

Since the publication of the original version of this review, we have found no new studies, and therefore the conclusions remain unchanged. Currently there is a lack of quality evidence regarding the effectiveness of spinal bracing for patients with MSCC. Spinal bracing may improve comfort and quality of life for some patients, but we are unable to make broad recommendations for practice based on this review. Consideration should be given to developing a randomised controlled trial.

\section{Policymakers}

This review highlights a strong need for future research to provide healthcare professionals with useful guidelines to inform clinical decision making and guidelines.

\section{Funders}

Research to examine this topic needs to be undertaken to inform future practice. The cost of such a trial would be low as the only intervention with an associated cost is the provision of an appropriate spinal brace for participants randomised to intervention. This is best addressed in the UK through NCRI
Supportive and Palliative Care Clinical Studies Group by expanding the remit of the National Cancer Research Institute Brain CSG in collaboration with the Supportive \& Palliative Care CSG.

\section{Implications for research}

\section{General}

Further research and exploration of best practice in MSCC on positioning, bracing, and spinal stability are required. There are sufficient cases to allow quick recruitment, but cases are spread across many primary cancer sites (lung, breast, colon, prostate, renal, colorectal, etc.). Protocols should most likely stratify by tumour type. There should be multidisciplinary involvement of orthotics, nursing, physiotherapy, and occupational therapy staff along with oncology and palliative care leads.

\section{Design}

Randomised controlled trials to measure the efficacy of bracing would be possible.

\section{Measurement (endpoints)}

Change in pain score, gait speed (timed 10-metre walk), and Barthel Index of Activities of Daily Living, which covers continence and motor function, may be appropriate scales to use in a prospective study along with a patient-reported quality-of-life measure. These measures could be performed at baseline and one month.

\section{Other}

Most patients are in the oncology wards before and during treatment for MSCC. By one month, they may be home or still in a hospital for rehabilitation or palliative care. A health economic evaluation would be valuable as part of the trial. Furthermore, descriptive and qualitative studies would be beneficial to clarify mobilisation and positioning from a physician, nursing, and patient point of view.

\section{ACKNOWLEDGEMENTS}

For this updated version of the review, we would like to thank Joanne Abbott, Trials Seach Co-ordinator, Cochrane Pain, Palliative and Supportive Care (PaPaS) Review Group for her help in updating the searches. We would also like to thank Anna Hobson, Managing Editor for Cochrane PaPaS Group, for her support in updating this review.

We would like to acknowledge the contributions of Marie Cox (MC) as an author and Sheena Moffat (SM) Information Service Advisor, who contributed to the original review but did not participate in this update.

For the original review, we acknowledged the support of Jessica Thomas, Managing Editor, Cochrane PaPaS Review Group, UK.

Cochrane Review Group funding acknowledgement: The National Institute for Health Research (NIHR) is the largest single funder of the Cochrane PaPaS Review Group.

Disclaimer: The views and opinions expressed therein are those of the authors and do not necessarily reflect those of the NIHR, National Health Service (NHS), or the Department of Health. 


\section{REFERE N C E S}

\section{References to studies excluded from this review}

Chi 2009 \{published data only\}

Chi JH, Gokaslan Z, McCormick P, Tibbs PA, Kryscio RJ, Patchell RA. Selecting treatment for patients with malignant epidural spinal cord compression, does age matter?. Spine 2009;34(5):431-5.

\section{Freundt 2010 \{published data only\}}

Freundt K, Meyners T, Bajrovic A, Basic H, Karstens JH, Adamietz IA, et al. Dose escalation for metastatic spinal cord compression in patients with relatively radioresistant tumors. Strahlentherapie und Onkologie 2010;186(4):218-23.

\section{Furstenberg 2009 \{published data only\}}

Furstenberg CH, Wiedenhofer B, Gerner HJ, Putx C. The effect of early surgical treatment on recovery in patients with metastatic compression of the spinal cord. The Journal of Bone and Joint Surgery 2009;91(2):240-4.

Galasko 1991 \{published data only (unpublished sought but not used)\}

Galasko CSB. Spinal instability secondary to metastatic cancer. The Journal of Bone and Joint Surgery 1991;73(1):104-8.

Ippolito 1998 \{published data only (unpublished sought but not used)\}

Ippolito V, Micheletti E, Saccalani M, Barbera F, Tonoli S, Motta C. Radiotherapy and spinal brace: still first-choice treatment for vertebral metastases from breast cancer. Chirurgia Degli Organi di Movimento 1998;83(1-2):177-83.

Rades 2010 \{published data only (unpublished sought but not used)\}

Rades D, Schild SE, Abrahm JL. Treatment of painful bone metastases. Nature Review Clinical Oncology 2010;7:220-9.

Sciubba 2010 \{published data only (unpublished sought but not used)\}

Sciubba DM, Gokaslan ZL. Are patients satisfied after surgery for metastatic spine disease?. The Spine Journal 2009;10:63-5.

Spinazze 2005 \{published data only (unpublished sought but not used)\}

Spinazze S, Caraceni A, Schrijvers D. Epidural spinal cord compression. Critical Reviews in Oncology Hematology 2005;56:397-406.

\section{Additional references}

\section{Benzel 2001}

Benzel EC. Biomechanics of Spine Stabilization. New York: Thieme International, 2001.

\section{Bilsky 1999}

Bilsky MH, Lis E, Raizer J, Lee H, Boland P. The diagnosis and treatment of metastatic spinal tumor. The Oncologist 1999;4(6):459-69.

\section{Bilsky 2006}

Bilsky M, Smith M. Surgical approach to epidural spinal cord compression. Hematology-Oncology Clinics of North America 2006;20(6):1307-17.

\section{Bilsky 2007}

Bilsky MH, Azeem S. The NOMS framework for decision making in metastatic cervical spine tumors. Current Opinion Orthopaedics 2007;18:263-9.

\section{Borm 2004}

Borm W, Gleixner M, Klasen J. Spinal tumors in co-existing degenerative spine disease - a differential diagnostic problem. European Spinal Journal 2004;13(7):633-8.

\section{Bunting 2001}

Bunting RW, Shea B. Bone metastasis and rehabilitation. American Cancer Society 2001;Cancer Supplement, 92(4):1020-8.

\section{Gasbarrini 2010}

Gasbarrini A, Li H, Cappuccio M, Mirabile L, Paderni S, Gerzi S, et al. Efficacy evaluation of a new treatment algorithm for spinal metastases. Spine 2010;35(15):1466-70.

\section{Gilbert 1978}

Gilbert RW, Kim JH, Posner JB. Epidural spinal cord compression from metastatic tumor: diagnosis and treatment. Annals of Neurology 1978;3(1):40-51.

\section{Heary 2001}

Heary RF, Bono CM. Metastatic spinal tumors. Neurosurgical Focus 2001;11(6):1-9.

\section{Higgins 2011}

Higgins JPT, Green S (editors). Cochrane Handbook for Systematic Reviews of Interventions Version 5.1.0. The Cochrane Collaboration, 2011. www.cochrane-handbook.org.

\section{Jacobs 1999}

Jacobs P. Malignant spinal cord compression. Palliative Care Today 1999;8(2):20-1.

\section{Kwok 2005}

Kwok Y, Regine WF, Patchell RA. Radiation therapy alone for spinal cord compression: Time to improve upon a relatively ineffective status quo. Journal of Clinical Oncology 2005;23(15):3308-10.

\section{Levack 2002}

Levack P, Graham J, Collie D, Grant R, Kidd J, Kunkler I, et al. Don't wait for a sensory level-listen to the symptoms: a prospective audit of the delays in diagnosis of malignant cord compression. Clinical Oncology 2002;14:472-80.

\section{Lewandrowski 2006}

Lewandrowski KU, McLain RF, Benzel EC. Bracing for patients with spinal tumours. In: McLain RF, Lewandrowski KU, Markman M, Bukowski RM, Macklis R, Benzel EC editor(s). Cancer in the 
Spine: Comprehensive Care. New Jersey: Humana Press Inc, 2006:337-41.

\section{Loblaw 1998}

Loblaw DA, Laperriere NJ. Emergency treatment of malignant extradural spinal cord compression: an evidence-based guideline. Journal of Clinical Oncology 1998;16:1613-24.

\section{Maher de Leon 1998}

Maher de Leon ME, Schell S, Rozental JM. Tumours of the spine and spinal cord. Seminars in Oncology Nursing 1998;14(1):43-52.

\section{Makris 1995}

Makris A, Kunkler IH. The Barthel Index in assessing the response to palliative radiotherapy in malignant spinal cord compression: a prospective audit. Clinical Oncology 1995;7:82-6.

\section{McClinton 2006}

McClinton A, Hutchison C. Malignant spinal cord compression, a retrospective audit of clinical practice at a UK regional cancer centre. British Journal of Cancer 2006;94:486-91.

\section{Mercadante 1997}

Mercadante S. Malignant bone pain: pathophysiology and treatment. Pain 1997;69(1-2):1-18.

\section{NICE 2008}

National Institute for Health and Clinical Excellence. Metastatic spinal cord compression, diagnosis and management of adults at risk of and with MSCC. National Collaborating Centre for Cancer 2008; Vol. Guideline 75.

\section{Obbens 1987}

Obbens EA, Posner JB. Handbook of the Spinal Cord. New York: Marcel Dekker, 1987.

\section{Patchell 2005}

Patchell RA, Tibbs PA, Regine WF, Payne R, Saris S, Kryscio RJ, et al. Direct decompressive surgical resection in the treatment of spinal cord compression caused by metastatic cancer: a randomised trial. The Lancet 2005;366(9486):643-8.

\section{Pease 2004}

Pease NJ, Harris RJ, Finlay IG. Development and audit of a care pathway for the management of patients with suspected malignant spinal cord compression. Physiotherapy 2004;90(1):27-34.

\section{Posner 1995}

Posner JB. Spinal Metastases. Philadelphia: FA Davis Company, 1995.

\section{Prasad 2005}

Prasad D, Schiff D. Malignant spinal-cord compression. The Lancet Oncology 2005;6:15-24.

\section{CHARACTERISTICS OF STUDIES}

Characteristics of excluded studies [ordered by study ID]

\section{Rades 2006}

Rades D, Fehlauer F, Schulte R, Veninga T, Lukas JA, Hiba Basic S, et al. Prognostic factors for local control and survival after radiotherapy of metastatic spinal cord compression. Journal of Clinical Oncology 2006;24(21):3388-93.

\section{RevMan 2014 [Computer program]}

The Nordic Cochrane Centre; The Cochrane Collaboration. Review Manager. Version 5.3. Copenhagen: The Nordic Cochrane Centre; The Cochrane Collaboration, 2014.

\section{Schiff 2003}

Schiff D. Spinal cord compression. Neurologic Clinics of North America 2003;21:67-86.

\section{Thomas 2006}

Thomas KC, Nosyk B, Fisher CG, Dvorak M, Patchell RA, Regine WF, et al. Cost-effectiveness of surgery plus radiotherapy versus radiotherapy alone for metastatic epidural spinal cord compression. International Journal of Radiation Oncology, Biology, Physics 2006; Vol. 66, issue 4:1212-8.

\section{Tokuhashi 2005}

Tokuhashi Y, Matsuzaki H, Oda H, Oshima M, Ryu J. A revised scoring system for preoperative evaluation of metastatic spinal tumor prognosis. Spine 2005;30(19):2186-91.

\section{Walji 2008}

Walji N, Chan AK, Peake DR. Common acute oncological emergencies: diagnosis, investigation and management. Postgraduate Medical Journal 2008;84(994):418-27.

\section{White 1978}

White AA, Panjabi MM. Clinical Biomechanics of the Spine. 1st Edition. Lippincott William \& Wilkins, 1978.

\section{White 1990}

White AA, Panjabi MM. Clinical Biomechanics of the Spine. 2nd Edition. Lippincott William \& Wilkins, 1990.

\section{Yarbro 2005}

Yarbro CH, Frogge MH, Goodman M. Cancer Nursing: Principles and Practice. 6th Edition. London: Jones and Bartlett, 2005.

\section{References to other published versions of this review Lee 2012}

Lee SH, Cox KM, Grant R, Kennedy C, Kilbride L. Patient positioning (mobilisation) and bracing for pain relief and spinal stability in metastatic spinal cord compression in adults. Cochrane Database of Systematic Reviews 2012, Issue 3. [DOI: 10.1002/14651858.CD007609.pub2] 


\begin{tabular}{ll}
\hline Study & Reason for exclusion \\
\hline Chi 2009 & $\begin{array}{l}\text { This randomised controlled trial did not address the specific outcomes of bracing and position- } \\
\text { ing specified within this review }\end{array}$ \\
\hline Freundt 2010 & Retrospective study \\
\hline Furstenberg 2009 & Retrospective clinical trial \\
\hline Galasko 1991 & Retrospective paper \\
\hline Ippolito 1998 & Retrospective study \\
\hline Rades 2010 & Review paper \\
\hline Sciubba 2010 & Commentary letter \\
\hline Spinazze 2005 & Review paper \\
\hline
\end{tabular}

\section{AP PENDICES}

\section{Appendix 1. Appendix: Search strategies for original review}

\section{Search details}

Database: MEDLINE (Ovid) (1950 - Week 4, January 2012)

1 Spinal Cord Compression/ (8856)

2 Spinal Neoplasms/ (10049)

3 (cord adj6 compress\$).mp. [mp=title, original title, abstract, name of substance word, subject heading word] (11700)

4 compress\$.mp. [mp=title, original title, abstract, name of substance word, subject heading word] (92673)

5 (epidural or extradural or extra-dural or "spinal cord" or "dural sac" or "cauda equina" or "spinal column").mp. [mp=title, original title, abstract, name of substance word, subject heading word] (169137)

6 metast\$.mp. [mp=title, original title, abstract, name of substance word, subject heading word] (309497)

74 and 6 (2802)

85 and 7 (1542)

93 and 6 (1440)

101 and 6 (1004)

114 or 6 (399368)

122 and 11 (4564)

138 or 9 or 10 or 12 (5459)

14 randomized controlled trial.pt. (317022)

15 controlled clinical trial.pt. (83278) 
(Continued)

16 randomized controlled trials/ (317022)

17 random allocation/ (72791)

18 double-blind method/ (112236)

19 single-blind method/ (15567)

2014 or 15 or 16 or 17 or 18 or 19 (466167)

21 limit 20 to animal (50437)

22 limit 20 to human (425291)

2321 and $22(10855)$

2421 not 22 (39582)

2520 not $24(426585)$

26 clinical trial.pt. (465272)

27 exp clinical trials/ (658195)

28 clin\$ with trial\$.tw. (1)

29 placebos/ (30346)

30 placebo\$.tw. (131982)

31 random\$.tw. (536852)

32 exp research design/ (291693)

3326 or 27 or 28 or 29 or 30 or 31 or 32 (1109414)

34 limit 33 to animal (137432)

35 limit 33 to human (969521)

3634 and 35 (36247)

3734 not 36 (101185)

3833 not $37(1008229)$

39 comparative study/ (1549101)

40 exp evaluation studies/ (158314)

41 follow-up studies/ (433321)

42 prospective studies/ (307204)

43 (control\$ or prospectiv\$ or volunteer\$).tw. (2410885)

4439 or 40 or 41 or 42 or $43(4045378)$

45 limit 44 to animal (1185597)

46 limit 44 to human (2811222)

4745 and 46 (268529)

4845 not $47(917068)$

4944 not $48(3128310)$ 
(Continued)

5025 or 38 or 49 (3563872)

5113 and 50 (1259)

Database: EBM Reviews - Cochrane Central Register of Controlled Trials (Ovid) (13th February 2012)

1 Spinal Cord Compression/ (176)

2 Spinal Neoplasms/ (53)

3 (cord adj6 compress\$).mp. [mp=title, original title, abstract, mesh headings, heading words, keyword] (227)

4 compress\$.mp. [mp=title, original title, abstract, mesh headings, heading words, keyword] (4198)

5 (epidural or extradural or extra-dural or "spinal cord" or "dural sac" or "cauda equina" or "spinal column").mp. [mp=title, original title, abstract, mesh headings, heading words, keyword] (9043)

6 metast\$.mp. [mp=title, original title, abstract, mesh headings, heading words, keyword] (11966)

74 and $6(137)$

85 and $7(94)$

93 and $6(90)$

101 and $6(85)$

114 or $6(16027)$

122 and $11(36)$

138 or 9 or 10 or $12(118)$

Database: EMBASE (Ovid) (1980 - Week 4, January 2012)

1 Spinal Cord Compression/ (10115)

2 Spinal Neoplasms/ (10648)

3 (cord adj6 compress\$).mp. [mp=title, abstract, subject headings, heading word, drug trade name, original title, device manufacturer, drug manufacturer name] (12916)

4 compress\$.mp. [mp=title, abstract, subject headings, heading word, drug trade name, original title, device manufacturer, drug manufacturer name] (120236)

5 (epidural or extradural or extra-dural or "spinal cord" or "dural sac" or "cauda equina" or "spinal column").mp. [mp=title, abstract, subject headings, heading word, drug trade name, original title, device manufacturer, drug manufacturer name] (204093)

6 metast\$.mp. [mp=title, abstract, subject headings, heading word, drug trade name, original title, device manufacturer, drug manufacturer name] (410521)

74 and $6(4386)$

85 and $7(2535)$

93 and $6(2282)$

101 and $6(1894)$

114 or $6(526371)$

122 and $11(3537)$

138 or 9 or 10 or $12(5610)$

14 controlled-study.sh. (3681534)

Positioning and spinal bracing for pain relief in metastatic spinal cord compression in adults (Review) 
(Continued)

15 crossover-procedure.sh. (31733)

16 double-blind-procedure.sh. (102763)

17 phase-3-clinical-trial.sh. (12924)

18 placebo\$.tw. (164540)

19 randomized-controlled-trial.sh. (296357)

20 single-blind-procedure.sh. (14735)

21 blind\$.tw. (215213)

22 comparative study.tw. (57320)

23 (control\$ adj1 trial\$).tw. (109556)

24 cross?over\$.tw. (40482)

25 factorial\$.tw. (17764)

26 random\$.tw. (679440)

27 or/14-26 (4206739)

28 human.sh. (12805189)

29 nonhuman.sh. (3780391)

3028 and 29 (700996)

3129 not 30 (3079395)

3227 not 31 (2789445)

3313 and 32 (489)

Database: CINAHL (EBSCO) (1982 - January 2012)

1 (MH "Spinal Cord Compression") (633)

2 (MH "Spinal Neoplasms") (797)

3 cord N6 compress* $(0)$

4 compress* $^{\star}(11478)$

5 epidural or extradural or extra-dural or "spinal cord" or "dural sac" or "cauda equina" or "spinal column" (23972)

6 metast $^{\star}(21071)$

7 S4 and S6 (376)

$8 \mathrm{~S} 5$ and S7 (285)

9 S3 and S6 (0)

$10 \mathrm{~S} 1$ and S6 (133)

$11 \mathrm{~S} 4$ or S6 (32173)

12 S2 and S11 (378)

$13 \mathrm{~S} 8$ or S9 or S10 or S12 (577)

14 (MH "Random Assignment") (123)

Positioning and spinal bracing for pain relief in metastatic spinal cord compression in adults (Review) 
(Continued)

15 (MH "Random Sample") (38)

16 (MH "Crossover Design") (34)

17 (MH "Clinical Trials+") (9473)

18 (MH "Comparative Studies") (217)

19 (MH "Control (Research)+") (60)

20 (MH "Factorial Design") (10)

21 (MH "Quasi-Experimental Studies") (37)

22 (MH "Nonrandomized Trials") (5)

23 (MH "Placebos") (655)

24 (MH "Meta Analysis") (827)

25 (MH "Clinical Nursing Research") or (MH "Clinical Research") (3081)

26 (MH "Community Trials") (9)

27 (MH "Experimental Studies") (306)

28 (MH "One-Shot Case Study") (6)

29 (MH "Pretest-Posttest Design") (13)

30 (MH "Solomon Four-Group Design") (2)

31 (MH "Static Group Comparison") (0)

32 (MH "Study Design") (2795)

33 (MH "Clinical Trials") (9188)

34 (MH "Systematic Review") (748)

35 TI random* (752)

$36 \mathrm{Tl}^{\text {singl }}{ }^{\star}$ or doubl* or tripl ${ }^{\star}$ or trebl ${ }^{\star}$ (51229)

37 TI blind* or mask* (14161)

38 S36 and S37 (5962)

39 TI cross?over ${ }^{\star}$ or placebo* or control ${ }^{\star}$ or factorial or sham (518186)

$40 \mathrm{TI}_{\text {clin }}^{\star}$ or intervention* or compar ${ }^{\star}$ or experiment ${ }^{\star}$ or preventive or therapeutic (736416)

41 TI trial* $(42588)$

42 S40 and S41 (29996)

43 TI counterbalance* or multiple baseline* or ABAB design* (526)

44 TI meta?analy* or systematic review* (26808)

45 S14 or S15 or S16 or S17 or S18 or S19 or S20 or S21 or S22 or S23 or S24 or S25 or S26 or S27 or S28 or S29 or S30 or S31 or S32 or S33 or S34 or S35 or S38 or S39 or S42 or S43 or S44 (553687)

46 S13 and S45 (127) 


\section{Appendix 2. Appendix: Search strategies for 2015 updated review}

\section{Cochrane CENTRAL (February 2012 - 31 March 2015)}

1 MeSH descriptor: [Spinal Cord Compression] this term only

$2 \mathrm{MeSH}$ descriptor: [Spinal Neoplasms] this term only

3 (cord near/6 compress ${ }^{\star}$ ):ti, ab, kw (Word variations have been searched)

4 compress ${ }^{\star}$ : ti, ab, kw (Word variations have been searched)

5 (epidural or extradural or extra-dural or "spinal cord" or "dural sac" or "cauda equina" or "spinal column"): ti, ab, kw (Word variations have been searched)

6 metast* $^{\star}$ ti, ab, kw (Word variations have been searched)

74 and 6

85 and 7

93 and 6

101 and 6

114 or 6

122 and 11

138 or 9 or 10 or 12

MEDLINE \& MEDLINE in Process (February 2012 - 31 March 2015)

1 Spinal Cord Compression/

2 Spinal Neoplasms/

3 (cord adj6 compress\$).mp.

4 compress\$.mp.

5 (epidural or extradural or extra-dural or "spinal cord" or "dural sac" or "cauda equina" or "spinal column").mp.

6 metast\$.mp.

74 and 6

85 and 7

93 and 6

101 and 6

114 or 6

122 and 11

138 or 9 or 10 or 12

14 randomized controlled trial.pt.

15 controlled clinical trial.pt.

16 randomized.ab.

17 placebo.ab.

18 drug therapy.fs.

Positioning and spinal bracing for pain relief in metastatic spinal cord compression in adults (Review) 
19 randomly.ab.

20 trial.ab.

21 or $/ 14-20$

22 exp animals/not humans.sh.

2321 not 22

2413 and 23

\section{EMBASE (February 2012 - 31 March 2015)}

1 Spinal Cord Compression/

2 Spinal Neoplasms/

3 (cord adj6 compress\$).mp.

4 compress\$.mp.

5 (epidural or extradural or extra-dural or "spinal cord" or "dural sac" or "cauda equina" or "spinal column").mp.

6 metast\$.mp.

74 and 6

85 and 7

93 and 6

101 and 6

114 or 6

122 and 11

138 or 9 or 10 or 12

14 random $\$ . t w$.

15 factorial\$.tw.

16 crossover\$.tw.

17 cross over\$.tw.

18 cross-over $\$$.tw.

19 placebo\$.tw.

20 (doubl\$ adj blind\$).tw.

21 (singl\$ adj blind\$).tw.

22 assign\$.tw.

23 allocat\$.tw.

24 volunteer\$.tw.

25 Crossover Procedure/

26 double-blind procedure.tw.

27 Randomized Controlled Trial/

28 Single Blind Procedure/

Positioning and spinal bracing for pain relief in metastatic spinal cord compression in adults (Review) 
29 or $/ 14-28$

30 (animal/ or nonhuman/) not human/

$3129 \operatorname{not} 30$

3213 and 31

AMED (February 2012 - 31 March 2015)

1 Spinal cord compression/

2 Spinal neoplasms/

3 (cord adj6 compress\$).mp. [mp=abstract, heading words, title]

4 compress\$.mp.

5 (epidural or extradural or extra-dural or "spinal cord" or "dural sac" or "cauda equina" or "spinal column").mp.

6 metast\$.mp.

74 and 6

85 and 7

93 and 6

101 and 6

114 or 6

122 and 11

138 or 9 or 10 or 12

CINAHL (February 2012 - 31 March 2015)

\section{S23 S13 AND S22}

\section{S22 S14 OR S15 OR S16 OR S17 OR S18 OR S19 OR S20 OR S21}

S21 (allocat* random*)

S20 (MH "Quantitative Studies")

S19 (MH "Placebos")

S18 placebo*

S17 (random* allocat*)

S16 (MH "Random Assignment")

S15 (Randomi?ed control ${ }^{\star}$ trial $^{\star}$ )

S14 (singl ${ }^{\star}$ blind $\left.{ }^{\star}\right)$ or $\left(\right.$ doubl $^{\star}$ blind $\left.{ }^{\star}\right)$ or $\left(\right.$ tripl $^{\star}$ blind $\left.{ }^{\star}\right)$ or $\left(\right.$ trebl $^{\star}$ blind $\left.^{\star}\right)$ or $\left(\right.$ trebl $^{\star}$ mask $\left.^{\star}\right)$ or $\left(\right.$ tripl $^{\star}$ mask $\left.^{\star}\right)$ or $\left(\right.$ doubl $^{\star}$ mask $\left.^{\star}\right)$ or $\left(\right.$ singl ${ }^{\star}$ mask $\left.^{\star}\right)$

S13 S8 OR S9 OR S10 OR S12

S12 S2 and S11

S11 S4 or S6

S10 S1 and S6

S9 S3 and S6 
S8 S5 and S7

S7 S4 and S6

S6 metast*

S5 epidural or extradural or extra-dural or "spinal cord" or "dural sac" or "cauda equina" or "spinal column"

S4 compress*

S3 cord N6 compress*

S2 (MH "Spinal Neoplasms")

S1 (MH "Spinal Cord Compression")

WHAT'S NEW

\begin{tabular}{lll}
\hline Date & Event & Description \\
\hline 23 September 2015 & Review declared as stable & $\begin{array}{l}\text { This review will be updated should any new evidence become } \\
\text { available. }\end{array}$ \\
\hline
\end{tabular}

\section{H I S T O R Y}

Protocol first published: Issue 1, 2009

Review first published: Issue 3, 2012

\begin{tabular}{lll}
\hline Date & Event & Description \\
\hline 31 March 2015 & New search has been performed & $\begin{array}{l}\text { This review has been updated to include the results of a new } \\
\text { search. The search was last run in March } 2015 .\end{array}$ \\
\hline 31 March 2015 & $\begin{array}{l}\text { New citation required but conclusions } \\
\text { have not changed }\end{array}$ & No new studies were identified and conclusions not changed. \\
\hline
\end{tabular}

\section{CONTRIBUTIONS OFAUTHORS}

Draft the protocol: MC, LK, CK

Develop a search strategy: MC, LK, CK, SM

Search for trials: MC, LK, CK, SHL, RG

Obtain copies of studies and updated search strategy February 2012: SHL

Select which studies to include: LK, CK, SHL, RG

Draft the final review: LK, CK, SHL, RG

Update search strategy and ongoing studies: 31 March 2015: SHL

Update version of this review: SHL, RG, CK, LK

\section{DECLARATIONS OF INTEREST}

Siew Hwa Lee: None known

Robin Grant: None known

Catriona Kennedy: None known

Lynn Kilbride: None known 


\section{SOURCES OF SUPPORT}

\section{Internal sources}

- Edinburgh Napier University, UK.

- NHS Lothian, UK.

\section{External sources}

- No sources of support supplied

\section{DIFFERENCES BETWEEN PROTOCOLANDREVIEW}

We have changed the title in the updated version to 'Positioning and spinal bracing for pain relief in metastatic spinal cord compression in adults' as the word mobilisation may be confusing. The original version was titled 'Patient positioning (mobilisation) and bracing for pain relief and spinal stability in metastatic spinal cord compression in adults'.

\section{IN DEX TERMS}

\section{Medical Subject Headings (MeSH)}

${ }^{\star}$ Braces; Joint Instability [ ${ }^{*}$ therapy]; Pain Management [ ${ }^{*}$ methods]; Patient Positioning [ ${ }^{*}$ methods]; Spinal Cord Compression [*complications]; Spinal Neoplasms [secondary]; Spine

\section{MeSH check words}

Humans 